\title{
Prediction of tensile strength of sawn timber: definitions and performance of indicating properties based on surface laser scanning and dynamic excitation
}

\author{
Andreas Briggert $\mathbb{D} \cdot$ Anders Olsson $\cdot$ Jan Oscarsson
}

Received: 14 November 2019/Accepted: 13 February 2020/Published online: 11 May 2020

(C) The Author(s) 2020

\begin{abstract}
The presence of wood irregularities such as knots are decisive for the mechanical properties of sawn timber, and efficient utilisation of timber requires methods by which grade determining properties can be predicted with high accuracy. In the glulam and sawmilling industries today, there is a potential and a need for more accurate prediction methods. This paper concerns the performance of a set of indicating properties calculated by means of data from surface laser scanning, dynamic excitation and X-ray scanning, the latter used to obtain boards' average density. A total number of 967 boards of Norway spruce originating from Finland, Norway and Sweden were used to determine statistical relationships between the indicating properties and the grade determining properties used to grade sawn timber into T-classes. Results show that the indicating properties give coefficients of determination to tensile strength as high as 0.70 . Furthermore, results also show that laser scanning of boards with sawn surface finish give basis for almost as accurate grading as what scanning of planed boards do. The results imply that more accurate
\end{abstract}

A. Briggert $(\bowtie) \cdot$ A. Olsson $\cdot$ J. Oscarsson

Department of Building Technology, Linnaeus

University, Växjö, Sweden

e-mail: andreas.briggert@lnu.se

A. Olsson

e-mail: anders.olsson@1nu.se

J. Oscarsson

e-mail: jan.oscarsson@lnu.se grading of timber into T-classes is possible by application of a new set of indicating properties. This paper is part one of a series of two papers. In the second paper, two models to derive settings and calculate yield in different strength classes using the indicating properties presented herein are compared and discussed.

Keywords Laser scanning - Fibre direction · Dynamic modulus of elasticity · Grading of timber . Norway spruce

\section{List of symbols}

$E_{\mathrm{a}, 90, \text { nom }}$ Lowest local axial MOE of the destructivly tested part of the board, calculated on the basis of observed fibre directions

$E_{\mathrm{b}, 90, \text { nom }} \quad$ Lowest local bending MOE of the destructivly tested part of the board, calculated on the basis of observed fibre directions

$E_{\text {dyn, } 12 \%}$ Axial dynamic MOE at a moisture content (MC) of $12 \%$

$E_{\mathrm{t}, 0} \quad$ Tensile MOE parallel to grain

$E_{\mathrm{t}, 0,12 \%} \quad$ Grade determining tensile MOE parallel to grain

$f_{\mathrm{t}, 0} \quad$ Tensile strength parallel to grain

$f_{\mathrm{t}, 0, h} \quad$ Grade determining tensile strength parallel to grain 
$\mathrm{IP}_{E, \mathrm{a}} \quad$ Indicating property (IP) for prediction of the grade determining properties (GDPs), derived by means of multiple linear regression using $E_{\mathrm{a}, 90 \text {,nom }}$ and $E_{\mathrm{dyn}, 12 \%}$ as predictor variables and the investigated GDP as dependent variable

$\mathrm{IP}_{E, \mathrm{~b}} \quad$ IP for prediction of the GDPs, derived by means of multiple linear regression using $E_{\mathrm{b}, 90, \text { nom }}$ and $E_{\mathrm{dyn}, 12 \%}$ as predictor variables and the investigated GDP as dependent variable

$\rho \quad$ Density of a small speciemen of clear wood cut near the board's fracture zone

$\rho_{12 \%} \quad$ Grade determining density

$\rho_{s} \quad$ Board density

$\rho_{s, 12 \%} \quad$ Board density at an MC of $12 \%$

$\mu \quad$ MC determined by oven-drying of a small sample of the board

$\mu_{s} \quad$ Board's MC measured by means of a pintype moisture meter

$r^{2} \quad$ Coefficient of determination

\section{Introduction}

This paper is the first paper in a series of two papers on prediction of grade determining properties, and procedures for grading sawn timber into T-classes for use as glulam lamellae.

\subsection{Background}

The presence of wood irregularities such as knots are decisive for the mechanical properties of sawn timber, and efficient utilisation of timber requires strength grading methods by which these properties can be predicted with high accuracy. In Europe strength grading is carried out in accordance with EN 14081-1 [1] and its supporting standards, and the grading is performed either visually (visual grading) or by application of grading machines (machine grading). In the first case, the grading is based on a board's visual appearance and the grade, or strength class, is determined either by a trained individual or by utilization of an optical scanner. In the second case, one or several board properties are measured nondestructively by means of an approved grading machine system and the obtained measurement results are used to calculate indicating properties (IPs) to the so-called grade determining properties (GDPs).

Sawn timber used as glulam lamellae are graded to T-classes. The GDPs applied for such classes are tensile strength and tensile modulus of elasticity (MOE), both determined in the longitudinal board direction, and density. The former two are obtained by means of a tensile test carried out in accordance with EN 408 [2], whereas the grade determining density is determined in accordance with EN 384 [3] using a small specimen of clear wood cut near the board's fracture zone.

By means of a board's calculated IPs and predetermined limits (settings) of the IPs for each strength class in a grading combination, a board is either assigned to a strength class or rejected. The latter means that at least one of the board's IPs is lower than the required setting for the lowest strength class in the grading combination.

Settings are determined in accordance with EN 14081-2 [4]. However, a new version of this standard [5] was recently published but at the time of writing there is a transition period between them. Two types of systems can be used according to these standards; either output-controlled systems or machine-controlled systems. For both these system types, settings are derived using IPs and GDPs for a sample of boards. Machine-controlled systems, which are the most frequently used types of system in Europe, are suitable for machines by which timber of various size, species or origin are graded. For such a system, a rather large sample (more than 900 boards) is required to derive permanent settings.

Several types of machines are certified for grading timber to T-classes. Some of these machines are based on measurements including one or several of the following methods: dynamic excitation, surface laser scanning, X-ray scanning and weighing. One of the most common grading methods on the European market is based on application of an IP calculated on the basis of axial resonance frequency and board length. The performance of this IP was evaluated in [6] using a sample of 457 Norway spruce (Picea abies) boards originating from Finland and Russia. The thickness of the boards were between 38 and $50 \mathrm{~mm}$ and the width between 100 and $200 \mathrm{~mm}$. Single linear regression between this IP and grade determining tensile strength in board direction resulted in a 
coefficient of determination $\left(r^{2}\right)$ of 0.53 . For the same sample, single linear regression between the IP and the grade determining tensile MOE, and between the IP and the grade determining density, resulted in coefficients of determination of 0.64 and 0.14 , respectively. These three coefficients of determination imply that this IP gives rather poor prediction of the GDPs, which also results in poor utilisation of the wood material.

Axial resonance frequency and board length are also used in combination with board density to calculate a board's axial dynamic MOE, which is employed as an IP in several grading machines. For the same sample as discussed in the previous paragraph [6], single linear regression between axial dynamic MOE and grade determining tensile strength resulted in an $r^{2}$ of 0.58 , and a corresponding regression between axial dynamic MOE and grade determining tensile MOE in the board direction gave an $r^{2}$ of 0.91 . The latter $r^{2}$-value indicates the significance of including board density when predicting the tensile MOE (cf. 0.91-0.64 which was obtained using the IP mentioned in the previous paragraph). Since board density is determined for each board in this grading method, the board density, rather than the axial dynamic MOE, can be used as IP for prediction of the grade determining density. Single linear regression between board density and grade determining density resulted in an $r^{2}$ of 0.91 .

On the market, one of the most accurate grading methods for prediction of tensile strength is based on an IP calculated using high-resolution density data, board dimensions and axial resonance frequency, see e.g. $[6,7]$. The high-resolution density data is obtained from X-ray scanning and since the density of knots is about twice as high as the density of the surrounding clear wood [8], X-ray scanning enables identification of knots. Thus, knowledge of size and location of knots is utilized in the definition of this IP. For the sample of 457 Norway spruce boards, an $r^{2}$ of 0.64 was obtained between this IP and the tensile strength in board direction.

Axial dynamic MOE and board density are suitable IPs for prediction of the grade determining tensile MOE and the grade determining density, respectively. However, to acquire a better material utilisation of sawn timber graded to T-classes, it is necessary to develop IPs by which grade determining tensile strength can be predicted with higher accuracy than what can be achieved using the methods described in the previous paragraphs.

Wood, which is usually approximated as an orthotropic material, exhibits high strength and stiffness in the fibre direction, whereas the performance of these properties are poorer in perpendicular directions [9-11]. Most fibres within a board are generally close to parallel with the board's longitudinal direction; small deviations may occur due to spiral grain and/or skew cutting and taper of the log. However, around and within knots, fibre directions deviate substantially from the board's longitudinal direction, thus decreasing the strength and stiffness of the board significantly.

The in-plane fibre direction at surfaces of Norway spruce can be determined using the so-called tracheid effect [12-14]. When a circular laser spot illuminates a wood surface, the laser light will scatter into the cell structure and transmit mainly in the longitudinal direction of the tracheids. Some of this light will be reflected back to the surface, and there enter a shape that resembles an ellipse. The major axis of this ellipse is oriented in a direction that is parallel with a projection of the fibres longitudinal direction onto the plane of the surface.

In the year 2015, a grading method utilising the tracheid effect was approved by CEN/TC124/WG2/ TG1 for grading of structural timber [15]. The procedure to determine the IP employed for predicting the bending strength of a board can be summarised as follows: firstly, by means of surface laser scanning and dynamic excitation, the in-plane fibre directions at the longitudinal surfaces and the axial resonance frequency, respectively, are determined. Secondly, by using the observed in-plane fibre directions, board dimensions and the axial dynamic MOE, a bending MOE-profile is calculated along the longitudinal direction of the board. The lowest value along this MOE-profile then defines an IP to bending strength. A detailed description of the method is given in [16]. For a sample including a total number of 936 boards, single linear regression between the described IP and bending strength resulted in an $r^{2}$ of 0.69 [15], which indicates that this IP represents one of the most accurate methods developed this far for grading of structural timber. For the same sample, the $r^{2}$ between axial dynamic MOE and bending strength was 0.53 .

Other research groups have also suggested IPs based on surface laser scanning and/or X-ray scanning. For example, [17] used data from surface laser 
scanning to model knots in boards and then suggested a number of different IPs based on knowledge of size and location of knots for prediction of strength. Some of the suggested IPs gave very high coefficients of determination to strength. However, since they only had access to experimental data for a limited number of boards, no evidence was actually presented regarding the performance of these IPs. Another research group working with strength prediction suggested an elaborate IP based on data from both surface laser scanning and X-ray scanning [18]. This IP has, however, not been applied for grading of sawn timber to T-classes.

\subsection{Purpose and aims}

The work presented in this paper was part of a fullscale investigation with the purpose of achieving a formal approval of grading sawn timber to T-classes using a grading method very similar to the one suggested in [16]. The results of the investigation are presented in two papers. The aims of the present paper are as follows:

I. To define and evaluate IPs based on axial dynamic MOE and on observed in-plane fibre directions on longitudinal board surfaces. This include evaluation of statistical relationships between IPs and GDPs used for grading of sawn timber into T-classes.

II. To evaluate the significance of the surface finish (sawn surfaces or planed surfaces) when performing laser scanning of boards, i.e. to evaluate how the IPs are affected when calculated on the basis of data from laser scanning of sawn rather than of planed board surfaces.

The second paper (Prediction of tensile strength of sawn timber: Models for calculation of yield in strength classes) [19] concerns two quite different models or procedures to determine settings for strength classes, and how the yield obtained depends on the model applied. Both models would be permitted according to the standard EN 14081-2 [4, 5].

\section{Material and equipment}

\subsection{Sampling of material}

Sampling of the material was carried out in accordance with the guidelines given in EN 14081-2 [4], clause 6.2.2, which can be summarised as follows: settings for a new machine-controlled system shall be derived using a sample comprising a minimum total number of 900 boards divided into at least four sub-samples. Each such sub-sample shall consist of at least 100 boards. Furthermore, boards included in the sample shall be representative of the timber source and have the most demanding surface finish as the one intended to be applied in the grading. Regarding the latter, and in accordance with the glulam standard EN 14080 [20], clause I.5.7, at the time when the adhesive is applied, the bonding surfaces of lamellae shall be clean, and, according to clause I.7.2, machining of lamellae shall, in general, be carried out not earlier than $24 \mathrm{~h}$ prior to bonding. A common way for glulam manufactures to fulfil these requirements is to have a planer installed in the production line and plane each lamella a short time before applying the adhesive. As a result, sawn timber used as glulam lamellae are generally graded before planing.

A total number of 1771 Norway spruce boards with sawn surface finish were sampled for the purpose of this study, and were delivered from eight different sawmills in Finland, Norway and Sweden. The locations of these sawmills are marked in Fig. 1.

The destructive test used to determine the GDPs of a board is both time-consuming and expensive. Thus, since the total number of sampled boards were almost twice as high as required by EN 14081-2 [4], such destructive tests were only carried out for roughly half the total number of the sampled boards. The GDPs were successfully obtained for a total number of 967 boards. This sample of 967 boards is from here on denoted the total sample. This total sample was divided, based on origin, into five sub-samples: (1) south Sweden, (2) mid-Sweden, (3) north Sweden, (4) Norway and (5) Finland, see Fig. 1.

Since one of the aims of this investigation was to investigate the significance of scanning sawn rather than planed surfaces of boards, i.e. to investigate how the planing of board surfaces affects the IPs defined below in this paper, it was necessary to carry out nondestructive measurements of weight, dimensions and 


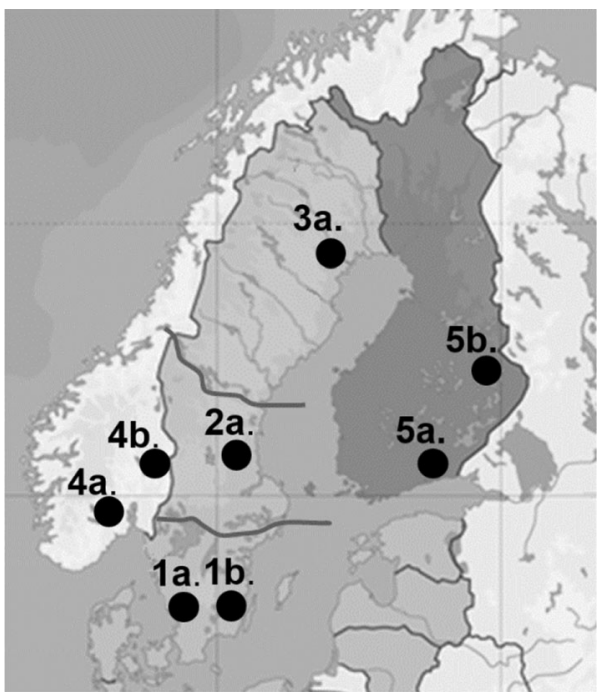

Fig. 1 Map showing origin of timber sub-samples from Finland, Norway and Sweden. The black dots mark the locations of the sawmills from which the timber originated

fibre directions both before and after planing. The resonance frequency was for most boards only determined before planing. However, as described in Sect. 2.3, similar frequencies were obtained before and after planing. Of course, destructive tests were made only after planing. Dimensions before and after planing, and number of boards in each of the subsamples, are given in Table 1.

Drying aiming at a $12 \%$ moisture content (MC) was applied for all sampled boards before any measurements were carried out. The moisture content of boards was, after drying, measured using a pin-type Delmhorst RDM $2 \mathrm{~S}$ moisture meter. The total sample's mean moisture content and standard deviation at the time of the non-destructive measurement were $12.4 \%$ and $1.7 \%$, respectively.

\subsection{Determination of fibre direction on board surfaces}

Local fibre directions on board surfaces were determined by means of a scanner of make WoodEye 5 [21], see Fig. 2a. This is a commercial optical wood scanner equipped with colour cameras, multi-sensor cameras, line lasers, dot-lasers etc., one set for each longitudinal board surface, see Fig. 2b. Each dot-laser is installed with a diffraction beam splitter, which scatters the laser light into 64 laser beams distributed along a line in the transversal board direction. A number of these laser beams will, as a board is fed through the scanner, illuminate one of the longitudinal board surfaces, see illustration in Fig. 2c. By means of photographs taken of the spread of laser light on board surfaces, in-plane fibre directions for every illuminated point are determined utilizing the tracheid effect, see Fig. 2d. The resolution of the observed in-plane fibre directions depends, in the transverse board direction, on the diffraction beam splitter and, in the longitudinal board direction, on the speed of the conveyor belts by which a board is transported through the scanner. The diffraction beam splitters installed in WoodEye 5 result in a transverse resolution of approximately $4 \mathrm{~mm}$. In this study, a speed of $200 \mathrm{~m} / \mathrm{min}$ was applied for all surface laser scans, resulting in a longitudinal resolution of approximately $2 \mathrm{~mm}$.

According to EN 14081-2 [4], clause 6.2.2, IPs used for deriving settings shall be calculated by means of board properties measured at the criticalfeed speed. All surface laser scans were made using the WoodEye 5 scanner available at Linnaeus University in Växjö, Sweden, and could not, due to safety reasons, be made at the critical feed speed $(450 \mathrm{~m} / \mathrm{min})$. It has, however, previously been shown that scanning speeds of $200 \mathrm{~m} /$ min and $450 \mathrm{~m} / \mathrm{min}$ result in practically identical IPs [15].

\subsection{Determination of resonance frequency and density}

The first axial longitudinal resonance frequency corresponding to the first mode of vibration of each board was determined using a Viscan strength-grading machine [22]. When a board passes by this machine, it is subjected to a hammer blow at one of the ends. At the same time, the oscillation at the same end is measured by a laser interferometer. By means of the measured vibrations and utilisation of Fast Fourier transform, the board's first axial longitudinal resonance frequency is calculated.

A Goldeneye 706 strength-grading machine [22], see Fig. 2f, was used to obtain each board's density. When a board is fed through this machine, it is exposed to radiation which is partially absorbed depending on the board's local density and MC. As a result, a high-resolution two-dimensional (2D) local density map is obtained for the entire board length. 


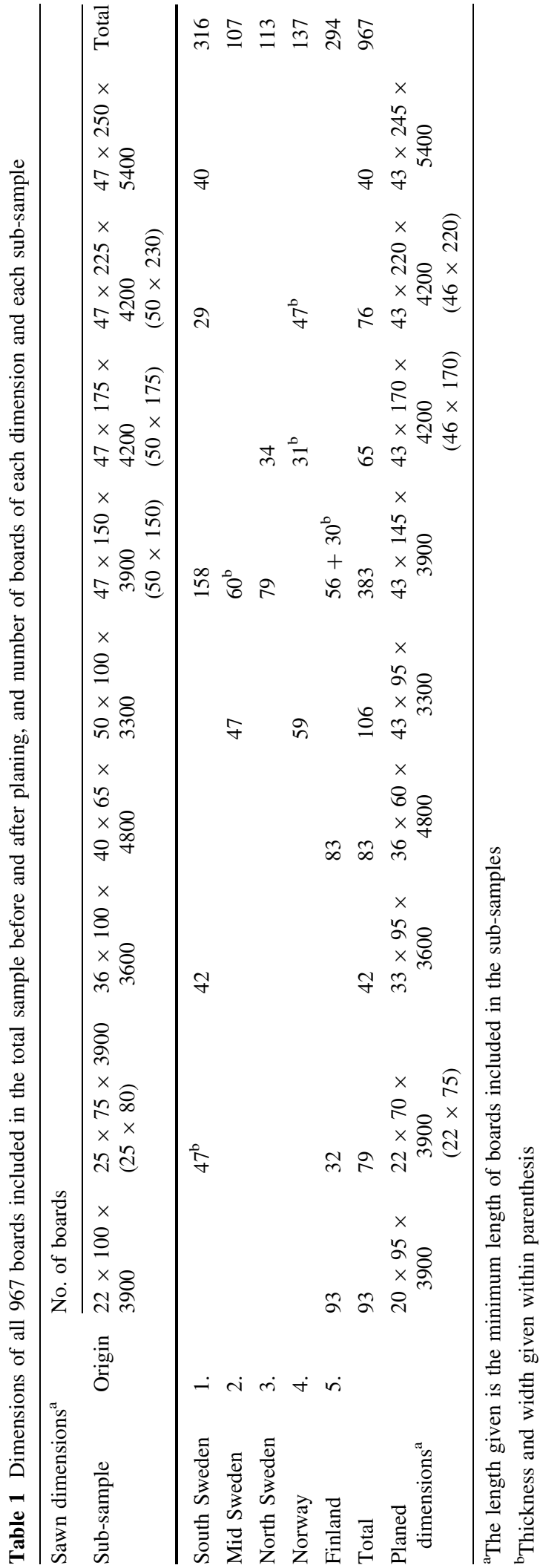

Board density can then be calculated as the average of all local density observations of such a 2D density map, or if the clear wood density is the target density, by calculating the average density of the knot free sections. An example of a 2D density map is shown in Fig. 2e, and the density can be interpreted using the colour bar to the left. Note that the part of the board that is displayed in Fig. 2e is the same part that is shown in Fig. 2c, d, but instead of showing only one wide surface as in $\mathrm{c}, \mathrm{d}$, the $2 \mathrm{D}$ density map represents the average density over the thickness direction of the board.

In the present study, the density of each board was also calculated using board dimensions and weight. The latter was obtained by weighing each board using a mechanical scale. The coefficients of determination between manually determined board densities and board densities obtained by Goldeneye 706 were 0.97 and 0.99 before and after planing, respectively.

The non-destructive measurements performed using Viscan and Goldeneye 706, respectively, and the planing of the boards, were carried out at the sawmill of Rörvik Timber in Myresjö, Sweden. Since one of the aims of this investigation was to compare the differences between IP values determined before and after planing, laser scanning of boards with sawn surfaces was carried out at Linnaeus University before the boards were transported to Myresjö. At the sawmill, the planer was located after the Viscan but before the Goldeneye 706. Thus, to obtain density measurements for unplaned boards using Goldeneye 706 , it was necessary to have the planer turned off at the first run of the boards through this system of machines. At the second run the planer was turned on, which meant that density measurements were carried out on boards with planed surfaces. However, the Viscan measurements carried out during both these runs were performed on boards having a sawn surface. To obtain the axial resonance frequency of each board after planing, it would have been necessary to run all boards through the machines a third time. Since the planer would have been turned off during such a third run, the feeder wheels of the planer could have damaged the board surfaces. A third run was, therefore, avoided, since the planed boards had to be laser scanned at Linnaeus University after the measurements at Myresjö and damages of the board surfaces could have resulted in inaccurately determined fibre directions. It has, however, previously been shown 


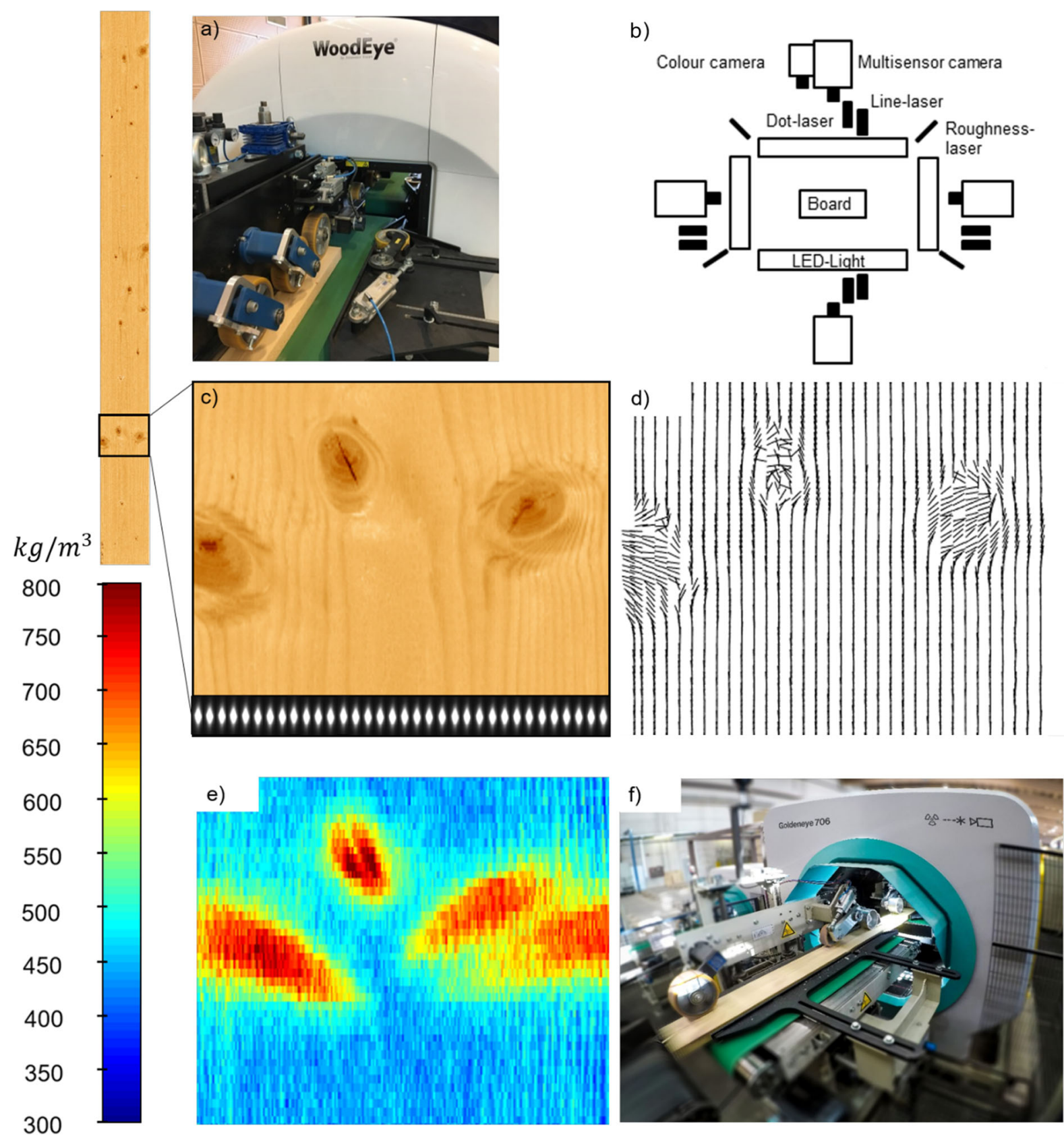

Fig. 2 a The optical wood scanner WoodEye 5, b setup of lasers and cameras in WoodEye 5, c illustration of laser spots resulting from laser beams illuminating a wood surface, d determined in-plane fibre directions for the surface exhibited

that similar resonance frequencies are obtained before and after planing [23]. Even so, for a number of 119 boards, the axial resonance frequencies were measured both before and after planing. For these boards, in $\mathbf{c}$ and $\mathbf{e}$ a 2D density map, obtained using Goldeneye 706, of the part of the board displayed in $\mathbf{c}$, and $\mathbf{f}$ the X-ray scanner Goldeneye 706

$r^{2}$ between axial resonance frequencies before and after planing was 0.99 , which shows that planing has a limited effect on resonance frequencies. 


\section{Determination of grade determining properties}

Sections 3.1, 3.2 and 3.3 describe the GDPs used for grading sawn timber to T-classes, and how these GDPs were determined, in accordance with EN 408 [2] and EN 384 [3], for all boards included in the total sample.

Regarding the term GDP, it is stated in EN 14081-2 [4], clause 3.5, with reference to EN 338 [3], that a GDP represents a property of the whole set of material graded to a certain strength class, namely a characteristic value of this material. However, the term is also used in connection to the property of an individual board, see for example EN 14081-2 [4], clause 3.6 and clauses 6.2.4.3-4. Herein, the terms grade determining density, grade determining MOE and grade determining strength refer to the properties of individual boards, which in turn give basis for calculation of characteristic values of a whole set of boards/material.

\subsection{Tensile strength in the board direction}

For each board included in the total sample, the tensile strength in the board direction was determined by a destructive test. The testing machine was of make MFL with a hydraulic force generator, with a maximum load capacity of $3.0 \mathrm{MN}$ and wedging type grips. The latter prevent rotation of the board ends. Each test was set up in such a way that a free test length of a minimum length of nine times the larger cross-section dimension was obtained, as required by EN 408 [2], clause 13.1. In the majority of the tests, and in accordance with EN 384 [3], clause 5.2, this free test length included the assumed weakest cross-section, i.e. the expected failure position. For boards for which the assumed weakest cross-section could not be included in the free test length, since this cross-section was located too close to one of the boards ends, the assumed second weakest cross-section was tested as permitted according to EN 384 [3], clause 5.2. The expected failure position of each board was determined by visual inspection.

In Fig. 3, the test setup of a board with nominal dimensions $46 \times 220 \mathrm{~mm}^{2}$ is shown. For boards with these dimensions the applied free test length, i.e. the length between the grips, was set to $2100 \mathrm{~mm}$, which was slightly larger than the required length of nine times the larger cross-section dimension. A compilation of required minimum free test length and applied free test length of all dimensions investigated in this research is given in Table 2 .

For a board destructively tested in tension, its tensile strength is calculated by

$f_{\mathrm{t}, 0}=\frac{F_{\max }}{b \cdot h}$

where $F_{\max }$ is the maximum applied tensile force, and $b$ and $h$ are the smaller and the larger cross-section dimensions, respectively. The tensile strength is then, in accordance with EN 384 [3], clause 5.4.3, adjusted by

$f_{\mathrm{t}, 0, h}=\frac{f_{\mathrm{t}, 0}}{k_{h}}$

where

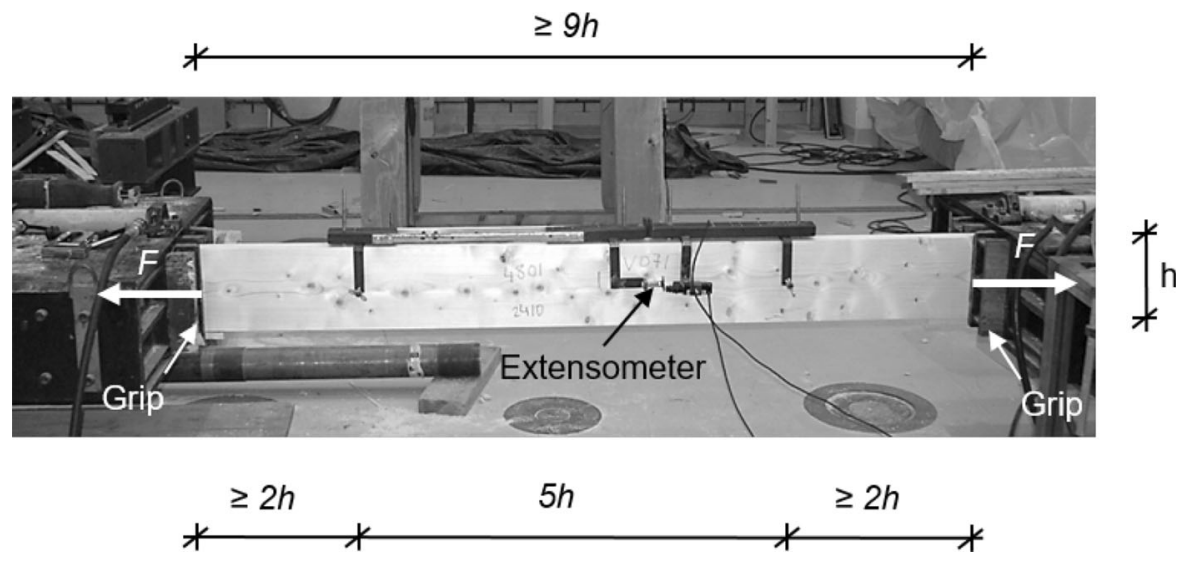

Fig. 3 Test setup for measuring tensile strength and tensile MOE in the board direction

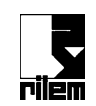


Table 2 Minimum free test lengths required according to EN 408:2010 together with applied free test length

\begin{tabular}{lcc}
\hline Dimensions $(\mathrm{mm})$ & Minimum free test length $(\mathrm{mm})$ & Applied free test length $(\mathrm{mm})$ \\
\hline $20 \times 95$ & 855 & 900 \\
$22 \times 70$ & 630 & 900 \\
$22 \times 75$ & 675 & 900 \\
$33 \times 95$ & 855 & 900 \\
$36 \times 60$ & 540 & 1000 \\
$43 \times 95$ & 855 & 900 \\
$43 \times 145$ & 1305 & 1400 \\
$43 \times 170$ & 1530 & 1700 \\
$46 \times 170$ & 1530 & 1700 \\
$43 \times 220$ & 1980 & 2100 \\
$46 \times 220$ & 1980 & 2100 \\
$43 \times 245$ & 2205 & 2250 \\
\hline
\end{tabular}

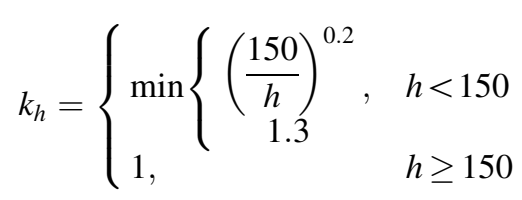

i.e. the experimentally determined tensile strength is reduced for all boards with $h$ smaller than $150 \mathrm{~mm}$. This adjustment is done to compensate for the so called size effect, meaning that smaller dimension board are less likely to contain serious defects and thus more likely to have high strength.

An additional requirement, given in EN 408 [2], clause 13.2, is that maximum tensile force in the destructive test should be reached within $300 \pm 120 \mathrm{~s}$, usually referred to as time to failure. A time to failure within this time span was aimed for in all tests. However, this requirement was not fulfilled for 113 out of the 967 tested boards; in two cases, the time to failure was almost $800 \mathrm{~s}$. The mean time to failure for all tests was $298 \mathrm{~s}$. Note that results also of boards not fulfilling the time span requirement are included in the results reported herein.

\subsection{Tensile modulus of elasticity in the board direction}

The tensile MOE of each board was determined from load- and deformation measurement data achieved from the straight-line portion of the load-deformation curve. Single linear regression was applied to the curve to obtain the slope of the regression line. The deformations were, in accordance with EN 408 [2], clause 12.2 , measured over a length of $5 h$ with a minimum distance of $2 h$ to each grip, see Fig. 3 . Furthermore, two extensometers were used, one for each side of the larger cross-section dimension, and positioned such that the deformations were measured at the centre of each of these two sides. The correlation coefficient between applied load and measured deformations was in all tests equal to or greater than 0.99 , i.e. in accordance with EN 408 [2], clause 12.3.

By means of the slope of the regression line, $k_{\mathrm{MOE}}$ $[\mathrm{N} / \mathrm{m}]$, each board's tensile MOE in the board direction is calculated as

$E_{\mathrm{t}, 0}=\left(\frac{l_{\mathrm{MOE}}}{b \cdot h}\right) \cdot k_{\mathrm{MOE}}$

where $b$ and $h$ are defined in the previous section and $l_{\mathrm{MOE}}$ is the length of the span over which the elongation is measured, i.e. $5 h$. The tensile MOE is then, in accordance with EN 384 [3], clause 5.4.2, adjusted by

$E_{\mathrm{t}, 0,12 \%}=E_{\mathrm{t}, 0} \cdot\left(1+\frac{1}{100} \cdot\left(\mu-\mu_{\mathrm{ref}}\right)\right)$

where $\mu$ is the $\mathrm{MC}$ of the board and $\mu_{\text {ref }}$ is the reference $\mathrm{MC}$ in a specimen at a relative humidity of $65 \%$ and a temperature of $20{ }^{\circ} \mathrm{C}$. For Norway spruce, the latter corresponds to an MC of $12 \%$. The MCs applied for calculating the GDPs were determined, in accordance with EN 408 [2] and EN 13183-1 [24], by oven-drying of a full cross-section specimen, free of knots and resin pockets, of each board cut as near as possible to the fracture zone. 


\subsection{Density}

The grade determining density of each board was, in accordance with EN 408 [2], clause 7, determined using a specimen free of knots and resin pockets cut out as near as possible to the fracture zone. These specimens were the same as those used when determining the MC, see Sect. 3.2. The weight of each specimen was determined using a mechanical scale and the volume by means of the water displacement method. The density, $\rho$, calculated by means of volume and weight of each such specimens was then, in accordance with EN 384 [3], clause 5.4.2, adjusted by

$\rho_{12 \%}=\rho \cdot\left(1-\frac{1}{200} \cdot\left(\mu-\mu_{\text {ref }}\right)\right)$

where $\mu$ and $\mu_{\text {ref }}$ are the MCs defined in Sect. 3.2.

\section{Definition and calculation of indicating properties}

In this section, the IPs used to predict the GDPs are defined. Section 4.1 concerns IPs calculated on the basis of measured fibre directions and dimensions. Section 4.2 concerns IPs calculated on the basis of resonance frequency, dimensions and density. In Sect. 4.3, IPs are defined on the basis of two predictor variables using multiple linear regression (here the two predictor variables are identical to two of the IPs defined in Sects. 4.1 and 4.2).

\subsection{Local axial and bending modulus of elasticity calculated on the basis of fibre directions and dimensions}

As mentioned in the introduction, $[15,16]$ employed IPs calculated on the basis of measured in-plane fibre direction for prediction of bending strength in sawn timber. In the following, very similar IPs for prediction of tensile strength are defined.

Optical wood scanners such as WoodEye 5 provide high-resolution data of the in-plane fibre directions at board surfaces. Here it is assumed that each observed fibre direction is valid for a certain small volume defined by $\mathrm{d} A \mathrm{~d} x$, see Fig. 4a-b. An illustration of measured in-plane fibre directions on a surface of length $\mathrm{d} x$ in the longitudinal direction of the board is shown in Fig. 4b. The size of the area $\mathrm{d} A$ is determined by the resolution of observed fibre directions in the transverse board direction and the dimensions of the cross-section, whereas the length of $\mathrm{d} x$ is determined by the resolution of observed fibre directions in the longitudinal board direction.

By means of the constitutive relationship of an orthotropic material, a transformation matrix based on the angle $(\varphi)$ between observed in-plane fibre direction and board direction, and nominal material parameters for Norway spruce, see Table 3, local MOEs in the board direction, i.e. $E_{x}(x, y, z)$, are calculated for each volume defined by $\mathrm{d} A \mathrm{~d} x$, for details see [16]. Note that only the in-plane angle of fibres is considered in the transformation matrix, i.e. the out-of-plane angle is disregarded. Photographs of all four surfaces of a part of a laser-scanned board are shown in Fig. 4c and the corresponding calculated values of $E_{x}(x, y, z)$ are exhibited in Fig. $4 \mathrm{~d}$; the relationship between colours and calculated values can be interpreted by the colour bar. In Fig. 4d it can be seen that the measured in-plane fibre directions within knots and their close surroundings result in low values of $E_{x}(x, y, z)$.

Longitudinal board stiffness (EA) and edgewise bending stiffness $\left(\mathrm{EI}_{y}\right)$, i.e. bending around the $y$-axis shown in Fig. 4a, are for each position $x$ (resolution given by $\mathrm{d} x$ ) calculated as

$\mathrm{EA}(x)=\iint E_{\mathrm{x}} \mathrm{d} y \mathrm{~d} z$

and

$\mathrm{EI}_{\mathrm{y}}(x)=\iint E_{\mathrm{x}} \cdot(z-\bar{z})^{2} \mathrm{~d} y \mathrm{~d} z$

respectively, where

$\bar{z}(x)=\frac{\int E_{\mathrm{x}} \cdot z \mathrm{~d} y \mathrm{~d} z}{\int E_{\mathrm{x}} \mathrm{d} y \mathrm{~d} z}$

By means of Eqs. 7, 8, axial and bending MOEs are calculated as

$E_{\mathrm{a}}(x)=\frac{\mathrm{EA}(x)}{b \cdot h}$

and

$E_{\mathrm{b}}(x)=\frac{12 \cdot \mathrm{EI}_{\mathrm{y}}(x)}{b \cdot h^{3}}$ 
(a)

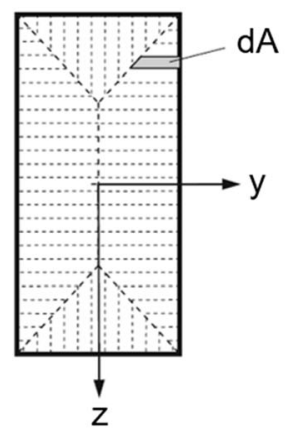

(c)
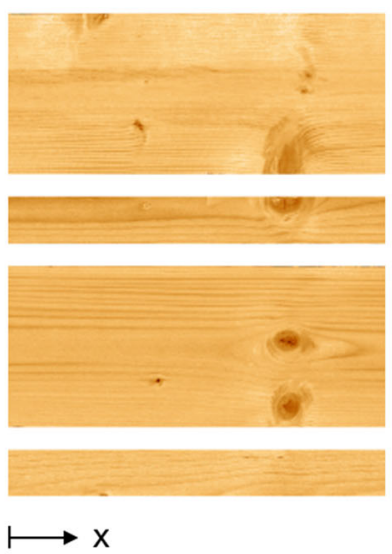

(b)

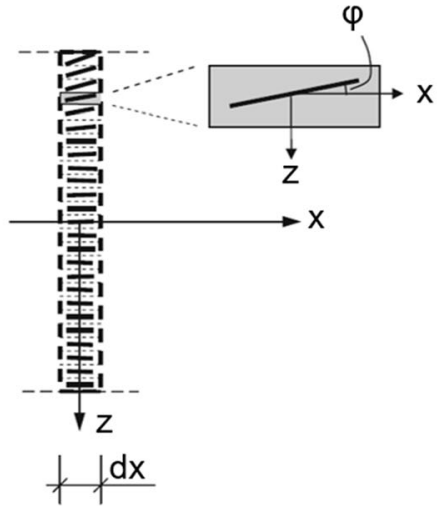

(d)
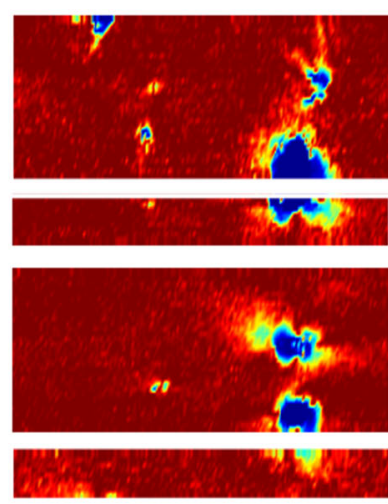

$\mathrm{GPa}$

10

8

6

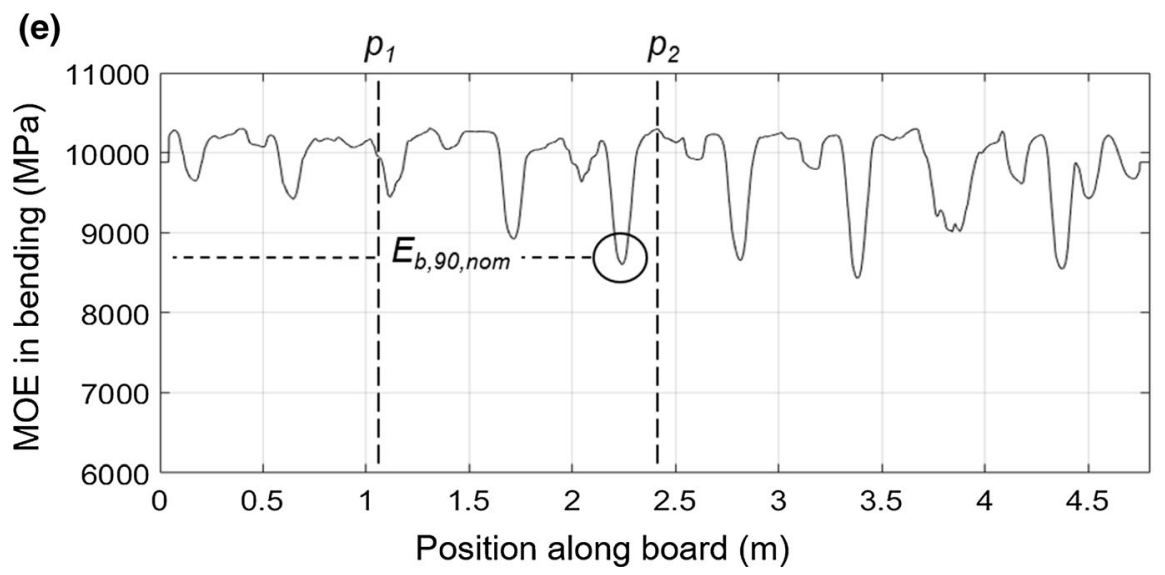

Fig. 4 a, b Illustration of the volume $\mathrm{d} A \mathrm{~d} x$ for which an observed in-plane fibre direction is assumed to be valid, c photographs of a board's surfaces, $\mathbf{d} E_{x}(x, y, z)$ calculated by means of observed in-plane fibre directions for the surfaces displayed in c, and e a bending MOE-profile based on the calculation of moving average MOE 
Table 3 Nominal material parameters employed for Norway spruce. Values originating from [25]

\begin{tabular}{ll}
\hline$E_{\mathrm{L}, 0}$ & $10,700 \mathrm{MPa}$ \\
$E_{\mathrm{R}, 0}$ & $710 \mathrm{MPa}$ \\
$E_{\mathrm{T}, 0}$ & $430 \mathrm{MPa}$ \\
$G_{\mathrm{LR}, 0}$ & $500 \mathrm{MPa}$ \\
$G_{\mathrm{LT}, 0}$ & $620 \mathrm{MPa}$ \\
$G_{\mathrm{RT}, 0}$ & $24 \mathrm{MPa}$ \\
$v_{\mathrm{LR}}$ & 0.38 \\
$v_{\mathrm{LT}}$ & 0.51 \\
$v_{\mathrm{RT}}$ & 0.51 \\
\hline
\end{tabular}

respectively. Using Eq. 10 for every position in the $x$ direction where fibre directions are observed results in a high-resolution axial MOE-profile. Similarly, Eq. 11 results in a high-resolution edgewise bending-MOE profile.

In [15] it was concluded that the highest coefficients of determination to bending strength is obtained if the lowest value along an MOE-profile representing a moving average over a length of $90 \mathrm{~mm}$ is applied as IPs rather than the lowest value of the high resolution MOE-profiles obtained by means of Eqs. 10, 11. An axial MOE profile based on a moving average of the MOE can be established on the basis of MOE calculated for different positions $x_{\mathrm{p}}$ along the board as

$\bar{E}_{\mathrm{a}}\left(x_{\mathrm{p}}, r\right)=\sum_{x=x_{\mathrm{p}} \pm r / 2} \frac{E_{\mathrm{a}}(x)}{r} \mathrm{~d} x$

where $r$ is the distance over which a moving average of the MOE is calculated (i.e. $r=90 \mathrm{~mm}$ ) and $\mathrm{d} x$ is the distance between two adjacent fibre observation in the longitudinal board direction; $x$ in Eq. 12 thus represents all discrete positions in the longitudinal board direction within the interval $x_{\mathrm{p}} \pm r / 2$ where fibre directions are observed. Similarly, for a bending MOE-profile, a moving average profile $\bar{E}_{\mathrm{b}}\left(x_{\mathrm{p}}, r\right)$ is calculated with $E_{\mathrm{b}}(x)$ as the numerator.

Based on Eqs. 10-12 two of the IPs evaluated herein can now be defined as

$E_{\mathrm{a}, 90, \text { nom }}=\min _{p_{1}<x_{\mathrm{p}}<p_{2}}\left(\sum_{x_{\mathrm{p}}=x_{\mathrm{p}} \pm 0.045} \frac{E_{\mathrm{a}}(x)}{0.09} \mathrm{~d} x\right)$

and

$E_{\mathrm{b}, 90, \text { nom }}=\min _{p_{1}<x_{\mathrm{p}}<p_{2}}\left(\sum_{x=x_{\mathrm{p}} \pm 0.045} \frac{E_{b}(x)}{0.09} \mathrm{~d} x\right)$ respectively, where $p_{1}$ and $p_{2}$ are the positions between which the MOE-profile is considered. As described in Sect. 3.1, the tensile strength in the board direction was only tested for a distance of approximately $9 h$, whereas the MOE-profiles are calculated for the entire board length. When evaluating the performance of the IPs defined in Eqs. 13 and 14, only the part of the board between the two grips was considered, i.e. the start and the end positions of the free test length were used as $p_{1}$ and $p_{2}$, respectively. Outside this length, the tensile strength is unknown. In this context, it should be mentioned that when actual grading is performed, $p_{1}$ and $p_{2}$ must be set such that the entire board length is considered. The indices 90 and nom in Eqs. 13 and 14 disclose that a moving average distance of $90 \mathrm{~mm}$ and nominal material parameters (see Table 3) are used.

Figure $4 \mathrm{e}$ shows a calculated bending MOE-profile representing a moving average over $90 \mathrm{~mm}$ for a board with dimensions $46 \times 220 \mathrm{~mm}$. The vertical dashed lines mark the positions $p_{1}$ and $p_{2}$ defining the test span. The lowest value of the profile between $p_{1}$ and $p_{2}$ define, in accordance with Eq. $14, E_{\mathrm{b}, 90 \text {,nom. }}$ Note that the distance between $p_{1}$ and $p_{2}$ is less than half the length of the board and that the MOE-profile indicates that there is actually a weaker section, at $x \approx 3.4 \mathrm{~m}$, than the weakest section between the grips.

\subsection{Axial dynamic modulus of elasticity and density}

Axial dynamic MOE is an IP often employed to predict both strength and stiffness. The axial dynamic MOE of a board, adjusted to a $12 \% \mathrm{MC}$, is calculated as

$E_{\mathrm{dyn}, 12 \%}=\rho_{s} \cdot\left(2 f_{1} L\right)^{2} \cdot\left(1+\frac{1}{100} \cdot\left(\mu_{s}-\mu_{\mathrm{ref}}\right)\right)$

where $\rho_{s}$ is the board density, $f_{1}$ is the board's axial resonance frequency corresponding to the first mode of vibration, $L$ is the board length and $\mu_{s}$ is the board's MC. The latter was in this study determined by measuring the MC using a pin-type moisture meter approximately $30 \mathrm{~cm}$ from one of the board ends. The density $\left(\rho_{s}\right)$ and the axial resonance frequency $\left(f_{1}\right)$ were determined using Goldeneye 706 (board density 
determined utilizing X-ray) and Viscan (resonance frequency determined utilizing an impact hammer and a laser vibrometer), respectively.

An IP suitable for prediction of the grade determining density was defined on the basis of the assessed board density, $\rho_{s}$. This IP is defined as

$\rho_{\mathrm{s}, 12 \%}=\rho_{s} \cdot\left(1-\frac{1}{200} \cdot\left(\mu_{s}-\mu_{\mathrm{ref}}\right)\right)$

\subsection{Indicating properties defined by means} of multiple linear regression

The IPs defined in Sect. 4.1, i.e. $E_{\mathrm{a}, 90, \text { nom }}$ and $E_{\mathrm{b}, 90 \text {,nom }}$, are based on local fibre directions specific for each board examined, and on values of material parameters that are representative for the species and not for each specific board. On the other hand, the IP $E_{\mathrm{dyn}, 12 \%}$ defined in Sect. 4.2 represents an average stiffness of each board. This IP depends both on board specific values of material parameters and on the influence of fibre deviation, but it does not give any knowledge of the variation of MOE along the board. Therefore, it makes sense to combine $E_{\mathrm{a}, 90 \text {,nom }}$ or $E_{\mathrm{b}, 90 \text {,nom }}$ with $E_{\mathrm{dyn}, 12 \%}$ to define new IPs by means of multiple linear regression. Mathematically these two new IPs are defined by

$$
\begin{aligned}
\operatorname{IP}_{E, \mathrm{a}}\left(E_{\mathrm{a}, 90, \mathrm{nom}}, E_{\mathrm{dyn}, 12 \%}\right)= & k_{0}+k_{1} \cdot E_{\mathrm{a}, 90, \text { nom }}+k_{2} \\
& \cdot E_{\mathrm{dyn}, 12 \%}
\end{aligned}
$$

and

$$
\begin{aligned}
I P_{\mathrm{E}, \mathrm{b}}\left(E_{\mathrm{b}, 90, \mathrm{nom}}, E_{\mathrm{dyn}, 12 \%}\right)= & k_{3}+k_{4} \cdot E_{\mathrm{b}, 90, \mathrm{nom}}+k_{5} \\
& \cdot E_{\mathrm{dyn}, 12 \%}
\end{aligned}
$$

respectively, where $k_{0}, k_{1}, k_{2}$ and $k_{3}, k_{4}, k_{5}$ are constants that define the planes best fitted to the scatters between the predictor variables and the dependent variable, i.e. the grade determining property, by the least square method. In $[15,16], E_{\mathrm{b}, 90, \text { nom }}$ and $E_{\mathrm{dyn}, 12 \%}$ were also used to define an IP (to bending strength) but they do not utilize multiple linear regression for definition of the combined IP. Instead, the two IPs are combined using a certain mechanical model.

\section{Results and discussion}

\subsection{Grade determining properties}

In Table 4, mean values (mean), standard deviation (std) and coefficient of variation $(\mathrm{CoV})$ of the three GDPs, i.e. $f_{\mathrm{t}, 0, h}, E_{\mathrm{t}, 0,12 \%}$ and $\rho_{12 \%}$, are presented for each of the five sub-samples and for the total sample. The results presented in Table 4 give an indication of the timber quality. The corresponding statistics was reported in [6] for a sample of 457 Norway spruce boards from Finland and Russia (in that sample, smaller cross-section dimensions ranged from 38 to $50 \mathrm{~mm}$ and larger cross section dimension ranged from 100 to $200 \mathrm{~mm}$ ) and the GDPs (mean values and standard deviations) of the two samples are very similar.

When comparing the properties of boards from different origin of the present sample it should be kept in mind that different sizes were sampled from different regions, see Table 1. For example, the subsample from Finland contained a higher proportion of small dimension boards than what the other subsamples did. Thus, differences between sub-samples may partly depend on differences of dimensions.

\subsection{Evaluation of results based on laser scanning}

In-plane fibre directions on board surfaces were, as described above, determined using laser scanning of both sawn surfaces and planed surfaces, i.e. each board was scanned both before and after planing. By comparing results from laser scanning made before and after planing, it could be seen that the in-plane fibre directions determined by the two different scans were, in most cases, very similar. For some boards, however, the laser scans carried out on rough sawn surfaces before planing, indicated irregular fibre directions also on knot-free surfaces. Of course, such observed irregularities do not represent the actual fibre directions within the board but only the disordered fibres of the rough surface itself. Examples of results of determined in-plane fibre directions of rough sawn surfaces are shown in Fig. 5a. The corresponding inplane fibre directions determined for the same board after planing is shown in Fig. $5 \mathrm{~b}$.

As regards axial and bending MOE-profiles with an applied moving average over $90 \mathrm{~mm}$, based on results from scanning before and after planing, respectively, 
Table 4 Mean value (mean), standard deviation (std) and coefficient of variation $(\mathrm{CoV})$ of the three GDPs

\begin{tabular}{|c|c|c|c|c|c|c|c|c|c|}
\hline \multirow[t]{2}{*}{ Sub-sample } & \multicolumn{3}{|c|}{$f_{\mathrm{t}, 0, h}\left(\mathrm{~N} / \mathrm{mm}^{2}\right)$} & \multicolumn{3}{|c|}{$E_{\mathrm{t}, 0,12 \%}\left(\mathrm{~N} / \mathrm{mm}^{2}\right)$} & \multicolumn{3}{|c|}{$\rho_{12 \%}\left(\mathrm{~kg} / \mathrm{m}^{3}\right)$} \\
\hline & mean & std & $\mathrm{CoV}$ & mean & std & $\mathrm{CoV}$ & mean & std & $\mathrm{CoV}$ \\
\hline South Sweden & 31.9 & 11.7 & 0.36 & 13,100 & 2500 & 0.19 & 466 & 45.0 & 0.10 \\
\hline Mid Sweden & 32.0 & 10.3 & 0.32 & 12,100 & 2400 & 0.20 & 451 & 42.9 & 0.10 \\
\hline North Sweden & 32.4 & 10.3 & 0.32 & 11,200 & 2200 & 0.19 & 433 & 37.4 & 0.09 \\
\hline Norway & 26.0 & 9.6 & 0.37 & 10,400 & 2100 & 0.21 & 424 & 43.5 & 0.10 \\
\hline Finland & 29.4 & 12.9 & 0.44 & 11,900 & 2800 & 0.24 & 441 & 42.2 & 0.10 \\
\hline All & 30.4 & 11.7 & 0.38 & 12,000 & 2700 & 0.22 & 447 & 45.3 & 0.10 \\
\hline
\end{tabular}

the irregularities of in-plane fibre directions related to rough sawn surfaces resulted in lower calculated axial and bending MOE compared to the corresponding MOEs calculated on the basis of fibre directions of planed surfaces. Figure 5c shows such calculated bending MOE-profiles of an entire board, and parts of one of the surfaces of the same board are exhibited in Fig. 5a, b. The black and red curves represent, respectively, the bending MOE-profiles calculated on the basis of in-plane fibre directions obtained from scanning before and after planing. The two curves follow each other well, but there is a vertical offset since the fibre distortions identified on the sawn surfaces resulted in a lower local MOE calculated in the direction of the board. Another example of bending MOE-profiles is shown in Fig. 5d. This example shows a case, representative for the majority of the examined boards, where the sawn surfaces were rather smooth. For such cases, the two calculated bending MOE-profiles, again based on results from scanning before (black curve) and after (red curve) planing, coincide very well.

An assessment of the overall significance of determining $E_{\mathrm{b}, 90 \text {,nom }}$ on the basis of scanning of sawn surfaces, rather than of planed surfaces, is done by calculating $r^{2}$ and standard error of estimate (SEE) for $E_{\mathrm{b}, 90, \text { nom }}$ based on data from sawn and planed surfaces, respectively. Furthermore, a relative difference (RD) between the average value of $E_{\mathrm{b}, 90 \text {,nom }}$ of a sample, based on data from sawn and planed surfaces, respectively, is calculated as

$\begin{aligned} \mathrm{RD}= & \left(1-\frac{\sum_{\text {all boards of selected sample }} E_{\mathrm{b}, 90, \text { nom,sawn }}}{\sum_{\text {all boards of selected sample }} E_{\mathrm{b}, 90, \text { nom,planed }}}\right) \\ & \cdot 100 \%\end{aligned}$ where $E_{\mathrm{b}, 90, \text { nom,sawn }}$ and $E_{\mathrm{b}, 90 \text {,nom,planed }}$ are a board's value of $E_{\mathrm{b}, 90, \text { nom }}$, see Eq. 14, before and after planing, respectively.

In Table 5, the relationship, in terms of $r^{2}$, SEE and $\mathrm{RD}$, between $E_{\mathrm{b}, 90 \text {,nom,sawn }}$ and $E_{\mathrm{b}, 90 \text {,nom,planed }}$ are presented, both for the total sample and separately for each cross-section dimension and origin/sawmill of which the total sample was composed. For the total sample, $r^{2}=0.96, \quad$ SEE $=212.8 \mathrm{MPa}$ and $\mathrm{RD}=$ $2.08 \%$ were obtained. As regards separate subsamples of boards of different cross-sectional dimension and origin/sawmill, results show that sub-samples containing boards of smaller dimensions give lower $r^{2}$, larger SEE and larger RD than what larger dimension sub-samples do. Of course, for sub-samples where many boards have very rough sawn surfaces, lower $r^{2}$, larger SEE and larger RD are obtained than for subsamples where boards have less rough sawn surfaces. It also make sense that results differ more between sawn and planed boards for small dimension boards than what it does for large dimension boards, since a rough spot on a sawn surface has, in percentage, greater influence for a small dimension board. As an example, the part of the board exhibited in Fig. 5a with sawn dimensions of $25 \times 80 \mathrm{~mm}$ belonged to a subsample with relatively low $r^{2}(0.92)$, relatively high SEE (233.3 MPa) and relatively high RD (2.79\%).

A corresponding comparison as the one presented for $E_{\mathrm{b}, 90, \text { nom }}$, is done for $E_{\mathrm{a}, 90, \text { nom }}$. For the total sample, a comparison of $E_{\mathrm{a}, 90 \text {,nom }}$ calculated on the basis of data from sawn and planed surfaces, respectively, gives $r^{2}=0.96$, SEE $=164.6 \mathrm{MPa}$ and $\mathrm{RD}=1.70 \%$. 


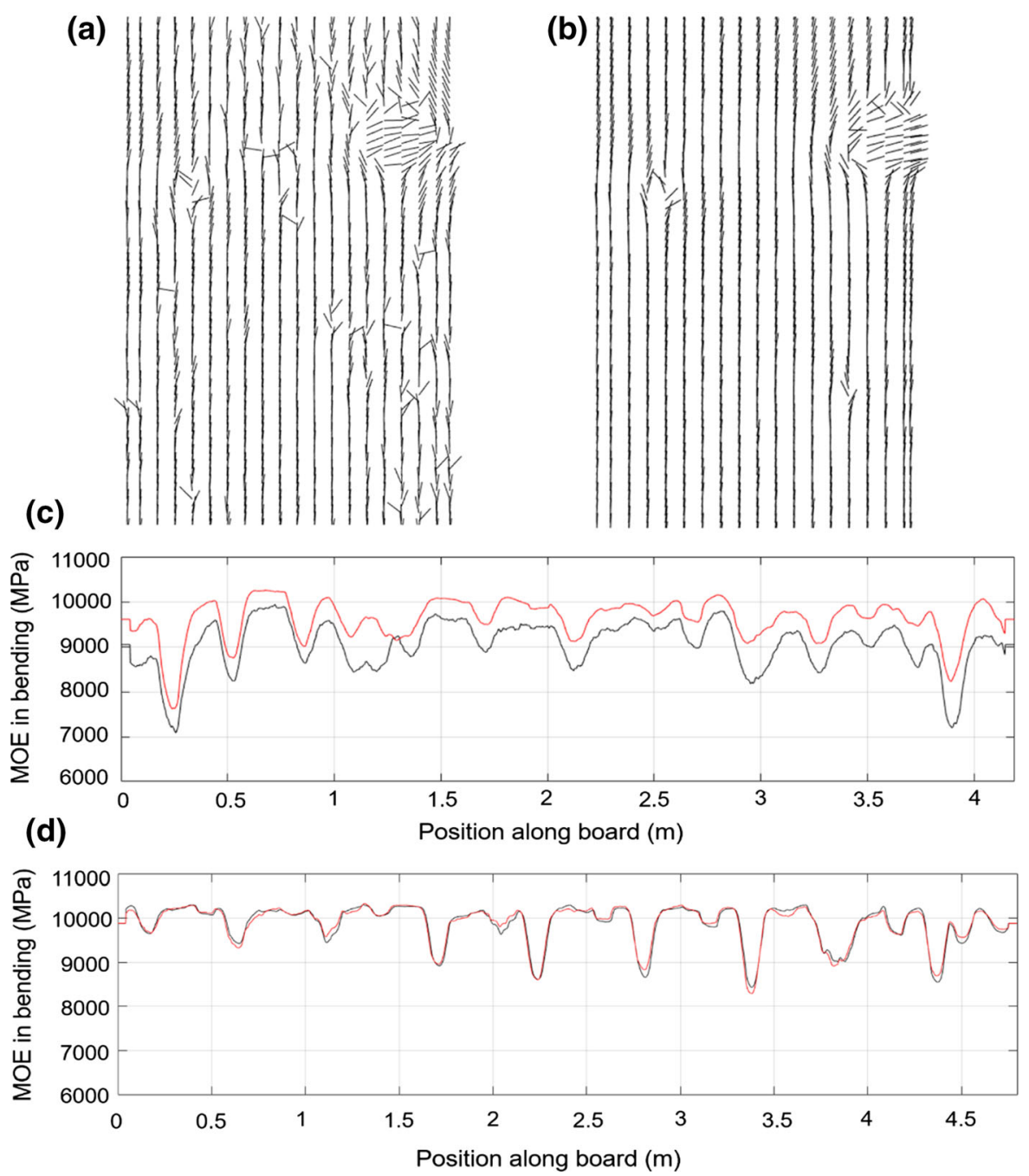

Fig. 5 a, b Determined in-plane fibre directions for a part of a board with sawn surface finish and planed surface finish, respectively, $\mathbf{c}$ bending MOE profiles before (black curve) and after (red curve) planing for the entire board which is partially

\subsection{Statistical relationships between indicating} properties and grade determining properties

All non-destructive measurements of boards, except axial resonance frequency, necessary for calculation of the IPs defined in Sects. 4.1, 4.2 and 4.3, were made both before and after planing. Results in terms of coefficients of determination and SEEs between IPs and GDPs are therefore presented for two different cases, i.e. for IPs calculated based on data of measurement obtained before and after planing, respectively. As regards the axial resonance displayed in $\mathbf{a}, \mathbf{b}$, and $\mathbf{d}$ bending MOE profiles for another board before (black curve) and after (red curve) planing. (Color figure online)

frequencies, these were only measured when the boards had sawn surface finish, i.e. before planing, but, as shown in Sect. 2.3, almost identical axial resonance frequencies are obtained before and after planing.

In Table 6, a compilation of coefficients of determination and SEEs based on linear regression between the different GDPs, and between the GDPs and the IPs defined in Sects. 4.1, 4.2 and 4.3, is presented. All coefficients of determination and SEEs given in Table 6 are calculated on the basis of the total sample of 967 boards. 
Table 5 Coefficients of determination, standard errors of estimate and relative differences of $\mathrm{E}_{\mathrm{b}, 90, \text { nom }}$ calculated by means of observed in-plane fibre directions measured before and after planing, respectively, i.e. $E_{\mathrm{b}, 90 \text {,nom,sawn }}$ versus $E_{\mathrm{b}, 90 \text {,nom,planed }}$

\begin{tabular}{|c|c|c|c|c|c|c|}
\hline Sawn dimension & Planed dimension & Origin (see Fig. 1) & Number of boards & $r^{2}$ & SEE (MPa) & $\mathrm{RD}(\%)$ \\
\hline $22 \times 100$ & $20 \times 95$ & $5 a$ & 60 & 0.96 & 220.4 & 1.18 \\
\hline $22 \times 100$ & $20 \times 95$ & $5 b$ & 33 & 0.98 & 168.4 & 1.76 \\
\hline $25 \times 75$ & $22 \times 70$ & $5 b$ & 32 & 0.98 & 221.6 & 2.89 \\
\hline $25 \times 80$ & $22 \times 75$ & $1 \mathrm{a}$ & 47 & 0.92 & 233.3 & 2.79 \\
\hline $36 \times 100$ & $33 \times 95$ & $1 \mathrm{~b}$ & 42 & 0.98 & 119.1 & 1.18 \\
\hline $40 \times 65$ & $36 \times 60$ & $5 a$ & 83 & 0.91 & 322.7 & 5.16 \\
\hline $47 \times 150$ & $43 \times 145$ & 1a & 48 & 0.96 & 189.7 & 2.29 \\
\hline $47 \times 150$ & $43 \times 145$ & $1 b$ & 110 & 0.98 & 115.5 & 0.99 \\
\hline $47 \times 150$ & $43 \times 145$ & $3 a$ & 79 & 0.97 & 147.9 & 2.37 \\
\hline $47 \times 150$ & $43 \times 145$ & $5 a$ & 56 & 0.94 & 179.8 & 1.38 \\
\hline $47 \times 175$ & $43 \times 170$ & $3 a$ & 34 & 0.98 & 152.9 & 2.73 \\
\hline $47 \times 225$ & $43 \times 220$ & $1 b$ & 29 & 0.99 & 103.8 & 2.42 \\
\hline $47 \times 250$ & $43 \times 245$ & $1 \mathrm{a}$ & 40 & 0.99 & 117.8 & 1.30 \\
\hline $50 \times 100$ & $43 \times 95$ & $2 \mathrm{a}$ & 47 & 0.93 & 241.6 & 2.12 \\
\hline $50 \times 100$ & $43 \times 95$ & $4 a$ & 59 & 0.95 & 244.3 & 0.83 \\
\hline $50 \times 150$ & $43 \times 145$ & $2 \mathrm{a}$ & 60 & 0.95 & 166.7 & 3.41 \\
\hline $50 \times 150$ & $43 \times 145$ & $5 b$ & 30 & 0.96 & 137.4 & 0.87 \\
\hline $50 \times 175$ & $46 \times 170$ & $4 \mathrm{~b}$ & 31 & 0.96 & 174.8 & 2.12 \\
\hline $50 \times 230$ & $46 \times 220$ & $4 b$ & 47 & 0.99 & 137.3 & 0.96 \\
\hline Total sample & Total sample & Total sample & 967 & 0.96 & 212.8 & 2.08 \\
\hline
\end{tabular}

For prediction of $f_{\mathrm{t}, 0, h}$, the highest coefficients of determination and the lowest SEE were, by far, obtained using either $\mathrm{IP}_{E, \mathrm{a}}$ or $\mathrm{IP}_{E, \mathrm{~b}}$. Achieved coefficients of determination using linear regression are, for these IPs, in the range of $0.64-0.66$. This can be compared with the coefficient of determination achieved using $E_{\mathrm{dyn}, 12 \%}$, which is 0.46 . Thus, data obtained from surface laser scanning, and utilized for calculation of local axial or local bending MOE, contributes considerably to improved grading accuracy. Furthermore, the performance of each of the different IPs, calculated on the basis of data from scanning of boards made before and after planing, was rather similar, although for some IPs the latter gave slightly higher accuracy. Thus accurate grading of planed boards can be performed before planing which is of great practical importance in production of glulam lamellae.

For prediction of $E_{\mathrm{t}, 0,12 \%}, \mathrm{IP}_{E, \mathrm{a}}$ and $\mathrm{IP}_{E, \mathrm{~b}}$ give, just as for prediction of $f_{\mathrm{t}, 0, h}$, the highest coefficients of determination $\left(r^{2}=0.82\right)$ and the lowest SEE. However, almost as accurate prediction of $E_{\mathrm{t}, 0,12 \%}$ is achieved using $E_{\mathrm{dyn}, 12 \%}\left(r^{2}=0.81\right)$. Furthermore, the results show that the best IP for prediction of $\rho_{12 \%}$ is, not surprisingly, $\rho_{s, 12 \%}$.

Scatter plots between $f_{\mathrm{t}, 0, h}$ and $\mathrm{IP}_{E, \mathrm{a}}$, and between $f_{\mathrm{t}, 0, h}$ and $\mathrm{IP}_{E, \mathrm{~b}}$, calculated by means of scanning results obtained before and after planing, are shown in Fig. 6a-d, respectively. The equations used to calculate $\mathrm{IP}_{E, \mathrm{a}}$ and $\mathrm{IP}_{E, \mathrm{~b}}$, i.e. the linear equations that give the highest coefficients of determination, are given on the horizontal axis of respective scatter plot. Displayed in each scatter plot is also its $r^{2}, S E E$ and line of regression. It can be noted that the scatters do not actually comply very well with a linear relationship, but indicate a non-linear relationship. Therefore, a non-linear regression analysis, using a second order polynomial function rather than a linear one, for the relationship between $f_{\mathrm{t}, 0, h}$ and $\mathrm{IP}_{E, \mathrm{a}}$, and $f_{\mathrm{t}, 0, h}$ and $\mathrm{IP}_{E, \mathrm{~b}}$, was performed as well. This gave coefficients of determination between $f_{\mathrm{t}, 0, h}$ and $\mathrm{IP}_{E, \mathrm{a}}$ of 0.67 and 0.68 , and between $f_{\mathrm{t}, 0, h}$ and $\mathrm{IP}_{E, \mathrm{~b}}$ of 0.68 and 0.70 , when $\mathrm{IP}_{E, \mathrm{a}}$ and $\mathrm{IP}_{E, \mathrm{~b}}$ were calculated on the basis of data from scanning before and after planing, respectively. 
Table 6 Coefficients of determination and standard errors of estimate between different GDPs, and between the GDPs and the IPs defined in Sects. 4.1, 4.2 and 4.3

${ }^{\mathrm{a} A x i a l}$ resonance frequencies measured before planing

\begin{tabular}{|c|c|c|c|c|c|c|}
\hline \multirow[t]{3}{*}{ IP } & \multicolumn{6}{|c|}{ Grade determining properties } \\
\hline & \multicolumn{2}{|l|}{$f_{\mathrm{t}, 0, h}$} & \multicolumn{2}{|c|}{$E_{\mathrm{t}, 0,12 \%}$} & \multicolumn{2}{|l|}{$\rho_{12 \%}$} \\
\hline & $r^{2}$ & SEE (MPa) & $r^{2}$ & $\operatorname{SEE}(\mathrm{GPa})$ & $r^{2}$ & $\operatorname{SEE}\left(\mathrm{kg} / \mathrm{m}^{3}\right)$ \\
\hline \multicolumn{7}{|l|}{$G D P$} \\
\hline$f_{\mathrm{t}, 0, h}$ & 1 & 0 & 0.48 & 1.92 & 0.23 & 39.65 \\
\hline$E_{\mathrm{t}, 0,12 \%}$ & 0.48 & 8.39 & 1 & 0 & 0.53 & 31.01 \\
\hline$\rho_{12 \%}$ & 0.23 & 10.20 & 0.53 & 1.83 & 1 & 0 \\
\hline \multicolumn{7}{|l|}{ Before planing } \\
\hline$\rho_{s, 12 \%}$ & 0.18 & 10.58 & 0.45 & 1.98 & 0.90 & 14.54 \\
\hline$E_{\mathrm{dyn}, 12 \%}$ & 0.46 & 8.54 & 0.81 & 1.18 & 0.68 & 25.61 \\
\hline$E_{\mathrm{a}, 90, \text { nom }}$ & 0.51 & 8.16 & 0.31 & 2.23 & 0.08 & 43.57 \\
\hline$E_{\mathrm{b}, 90, \text { nom }}$ & 0.48 & 8.44 & 0.25 & 2.32 & 0.05 & 44.24 \\
\hline $\operatorname{IP}_{E, \mathrm{a}}\left(E_{\mathrm{a}, 90, \text { nom }}, E_{\mathrm{dyn}, 12 \%}\right)$ & 0.64 & 6.98 & 0.82 & 1.15 & 0.71 & 24.39 \\
\hline $\operatorname{IP}_{E, \mathrm{~b}}\left(E_{\mathrm{b}, 90, \text { nom }}, E_{\mathrm{dyn}, 12 \%}\right)$ & 0.65 & 6.93 & 0.82 & 1.15 & 0.71 & 24.42 \\
\hline \multicolumn{7}{|l|}{ After planing } \\
\hline$\rho_{s, 12 \%}$ & 0.19 & 10.53 & 0.48 & 1.94 & 0.92 & 12.58 \\
\hline$E_{\mathrm{dyn}, 12 \%}^{\mathrm{a}}$ & 0.46 & 8.54 & 0.81 & 1.18 & 0.68 & 25.61 \\
\hline$E_{\mathrm{a}, 90, \text { nom }}$ & 0.52 & 8.06 & 0.32 & 2.21 & 0.08 & 43.45 \\
\hline$E_{\mathrm{b}, 90, \text { nom }}$ & 0.51 & 8.17 & 0.27 & 2.29 & 0.06 & 44.07 \\
\hline $\operatorname{IP}_{E, \mathrm{a}}\left(E_{\mathrm{a}, 90, \text { nom }}, E_{\mathrm{dyn}, 12 \%}^{\mathrm{a}}\right)$ & 0.65 & 6.95 & 0.82 & 1.15 & 0.71 & 24.42 \\
\hline $\operatorname{IP}_{E, \mathrm{~b}}\left(E_{\mathrm{b}, 90, \text { nom }}, E_{\mathrm{dyn}, 12 \%}^{\mathrm{a}}\right)$ & 0.66 & 6.79 & 0.82 & 1.14 & 0.71 & 24.32 \\
\hline
\end{tabular}

\section{Conclusion}

Results presented in this paper concerns statistical relationships between IPs calculated on the basis of laser scanning and dynamic excitation, and boards' GDPs. The results are based on investigations of a total number of 967 boards of Norway spruce originating from Finland, Norway and Sweden. Sampling and destructive testing of these boards were carried out in accordance with European standards.

All boards were laser scanned for assessment of inplane fibre direction, firstly when the boards had a sawn surface finish and then again after planing. For most of the boards, the in-plane fibre directions obtained before and after planing, corresponded to a large extent. For some boards, however, laser scans carried out before planing on rough sawn surfaces indicated irregular fibre directions even on knot-free surfaces. It is a well-known fact that different types of sawing equipment, and the different types of blades installed in them, may result in different levels of surface roughness. Thus, if grading is based on laser scanning of surfaces before planing it may be crucial not to use equipment that give very rough surfaces.

The IPs obtained by multiple linear regression, i.e. $\mathrm{IP}_{E, \mathrm{a}}$ and $\mathrm{IP}_{E, \mathrm{~b}}$, resulted in higher coefficients of determination and lower SEEs for $f_{\mathrm{t}, 0, h}$ than other IPs, which are, however, often employed in industry. For example, linear regression between $f_{\mathrm{t}, 0, h}$ and $\mathrm{IP}_{E, \mathrm{~b}}$ calculated by means of measurement results obtained before and after planing resulted in coefficients of determination of 0.65 and 0.66 , respectively. Using non-linear regression between $f_{\mathrm{t}, 0, h}$ and $\mathrm{IP}_{E, \mathrm{~b}}$ resulted in coefficients of determinations as high as 0.68 when $\mathrm{IP}_{E, \mathrm{~b}}$ was determined before planing and 0.70 when it was determined after planing. In fact, by comparing the results obtained in this investigation with the results given in [6], it can be expected that the performance of both $\mathrm{IP}_{E, \mathrm{a}}$ and $\mathrm{IP}_{E, \mathrm{~b}}$, as regards prediction of tensile strength in board direction, will surpass the most accurate commercially available IPs used in grading machines today.

All the IPs defined in this paper, except $E_{\mathrm{dyn}, 12 \%}$ and $\rho_{s, 12 \%}$, represent only the part of each board that was placed between the grips when evaluating the 
(a) $\quad I P_{\mathrm{E}, \mathrm{a}}$ before planing

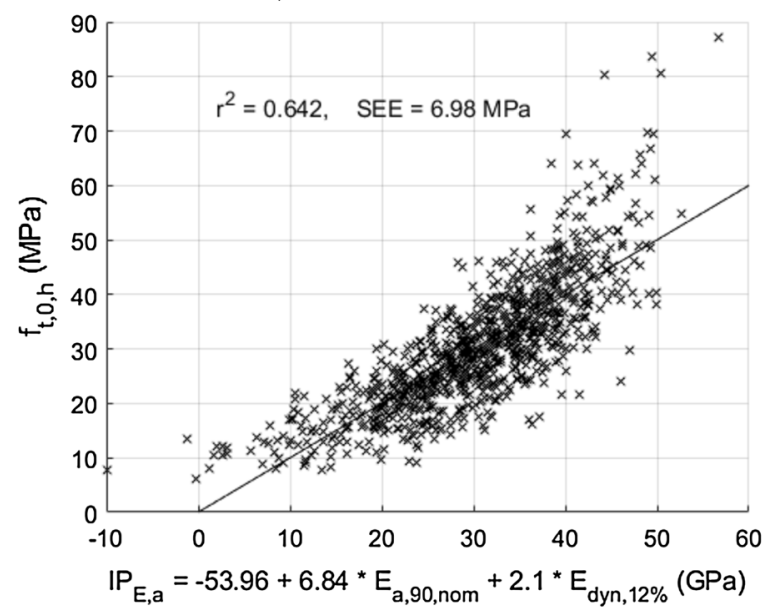

(c) $\quad I P_{\mathrm{E}, \mathrm{b}}$ before planing

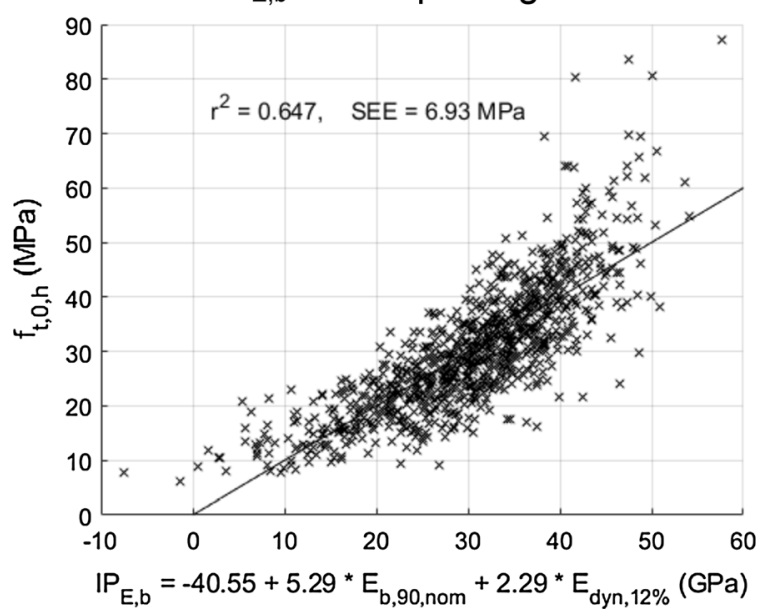

(b) $\quad P_{\mathrm{E}, \mathrm{a}}$ after planing

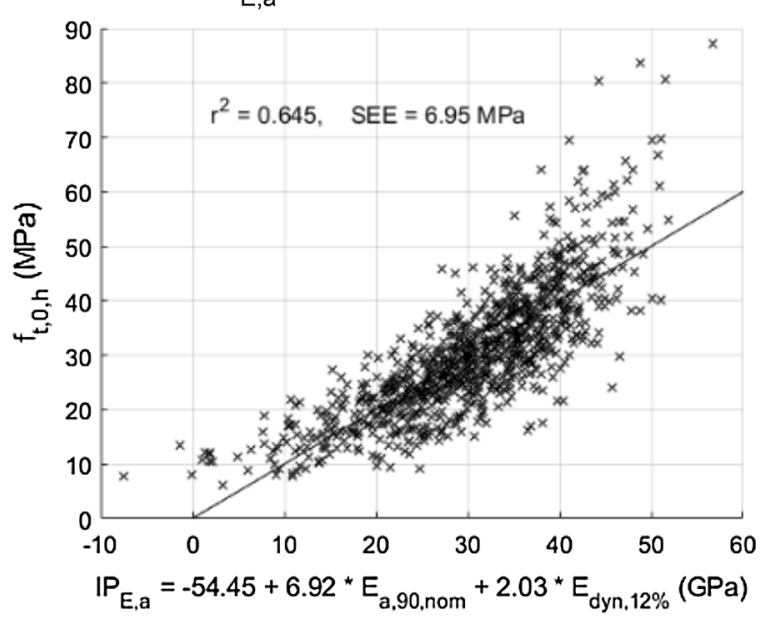

(d)

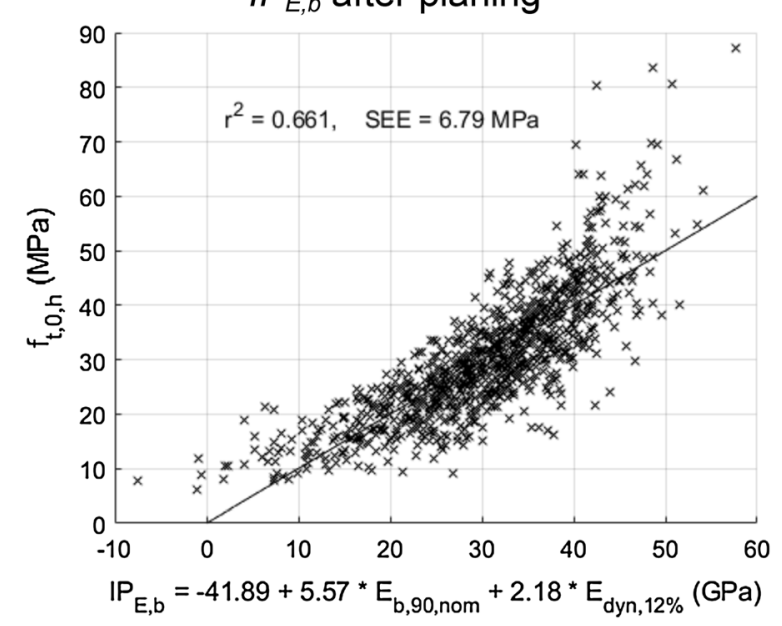

Fig. 6 a, b Scatter plots between $\operatorname{IP}_{E, \mathbf{a}}$ and $f_{\mathrm{t}, 0, h}$, and c, $\mathbf{d}$ between $\operatorname{IP}_{E, \mathbf{b}}$ and $f_{\mathrm{t}, 0, h}$

maximum load that determined $f_{\mathrm{t}, 0, h}$. When assessing the ability of different methods to predict strength, which was the purpose of the present paper, it is reasonable to calculate IPs on the basis of this part of the board. However, the part of the board that was placed between the grips was usually less than half of the length of the board, which means that many boards actually had sections with lower strength somewhere else along it. Moreover, if the IPs (except $E_{\mathrm{dyn}, 12 \%}$ and $\rho_{s, 12 \%}$ ) were defined in such a way that they represented the entire length of the board, many boards would be assigned lower values for the IPs, i.e. lower than what is the case when only the part of the board between the grips is considered. When grading boards into strength classes the entire length must be considered. However, there are at least two, quite different procedures/models that can be adopted for this purpose. Both would be permitted with respect to requirements of EN14081-2 [4] and EN 14081-2 [5] but they give quite different results in terms of yield in strength classes. Since this is the case, the alternative models must be described, compared and discussed in detail and this is an objective of Prediction of tensile strength of sawn timber: Models for calculation of yield in strength classes [19] in this series of two papers. Another objective of [19] is to present 
calculated yield in different T-classes, and combinations of T-classes.

Acknowledgements Open access funding provided by Linnaeus University. The authors acknowledge the support from Derome Timber, Loab, Microtec, Moelven Töreboda AB, Rörvik Timber AB, Södra Innovasion \& Nya affärer and WoodEye.

Funding This study was funded by the Knowledge Foundation (Grant No. 20150179).

\section{Compliance with ethical standards}

Conflict of interest The authors declare that they have no conflict of interest.

Open Access This article is licensed under a Creative Commons Attribution 4.0 International License, which permits use, sharing, adaptation, distribution and reproduction in any medium or format, as long as you give appropriate credit to the original author(s) and the source, provide a link to the Creative Commons licence, and indicate if changes were made. The images or other third party material in this article are included in the article's Creative Commons licence, unless indicated otherwise in a credit line to the material. If material is not included in the article's Creative Commons licence and your intended use is not permitted by statutory regulation or exceeds the permitted use, you will need to obtain permission directly from the copyright holder. To view a copy of this licence, visit http://creativecommons.org/licenses/by/4.0/.

\section{References}

1. EN 14081-1 (2016) Timber structures-strength graded structural timber with rectangular cross section-part 1: general requirements. European Committee for Standardisation, Brussels

2. EN 408 (2010) + A1 (2012) Timber structures-structural timber and glued laminated timber-determination of some physical and mechanical properties. European Committee for Standardisation, Brussels

3. EN 384 (2016) + A1 (2018) Structural timber-determination of characteristic values of mechanical properties and density. European Committee for Standardisation, Brussels

4. EN 14081-2 (2010) + A1 (2012) Timber structuresstrength graded structural timber with rectangular cross section-part 2: machine grading; additional requirements for initial type testing. European Committee for Standardisation, Brussels

5. EN 14081-2 (2018) Timber structures-strength graded structural timber with rectangular cross section-part 2 : machine grading; additional requirements for initial type testing. European Committee for Standardisation, Brussels

6. Hanhijärvi A, Ranta-Maunus A (2008) Development of strength grading of timber using combined measurement techniques. Report of the Combigrade-project-phase 2, vol 686. VTT Publications, p 55
7. Bacher M (2008) Comparison of different machine strength grading principles. In: Proceedings of 2 nd conference of COST action E53-quality control for wood and wood products, Delft, The Netherlands, 29-30 Oct

8. Schajer SG (2001) Lumber strength grading using X-ray scanning. For Prod J 51(1):43-50

9. Hankinson RL (1921) Investigation of crushing strength of spruce at varying angles of grain. Air Service Information Circular, 3(259), Material section report no. 130, US Air Service, USA

10. Kollman FFP, Côté WA (1968) Principles of wood science and technology. Springer, Berlin

11. Hatayama Y (1984) A new estimation of structural lumber considering the slope of grain around knots. Bulletin of the Forestry and the Forest Products Research Institute, No. 326:69-167, Japan (in Japanese)

12. Matthews PC, Beech BH (1976) Method and apparatus for detecting timber defects. U.S. Patent no. 3976384

13. Soest J, Matthews P, Wilson B (1993) A simple optical scanner for grain defects. In: Proceedings of the 5th international conference on scanning technology \& process control for the wood products industry. Atlanta, GA, USA, 25-27 Oct

14. Briggert A, Olsson A, Oscarsson J (2018) Tracheid effect scanning and evaluation of in-plane and out-of-plane fibre direction in Norway spruce timber. Wood Fiber Sci 50(4):1-19

15. Olsson A, Oscarsson J (2017) Strength grading on the basis of high resolution laser scanning and dynamic excitation: a full scale investigation of performance. Eur J Wood Wood Prod 75:17-31

16. Olsson A, Oscarsson J, Serrano E, Källsner B, Johansson M, Enquist B (2013) Prediction of timber bending strength and in-member cross-sectional stiffness variation on the basis of local wood fibre orientation. Eur J Wood Wood Prod 71:319-333

17. Lukacevic M, Fussl J, Eberhardsteiner J (2015) Discussion of common and new indicating properties for the strength grading of wooden boards. Wood Sci Technol 49:551-576

18. Viguer J, Bourreau D, Bocquet J-F, Pot G, Bléron L, Lanvin J-D (2017) Modelling mechanical properties of spruce and Douglas fir timber by means of $\mathrm{X}$-ray and grain angle measurements for strength grading purpose. Eur J Wood Wood Prod 75:527-541

19. Briggert A, Olsson A, Oscarsson J (2020) Prediction of tensile strength of sawn timber: models for calculation of yield in strength classes. Mater Struct 53(3). https://doi.org/ 10.1617/s11527-020-01485-w

20. EN 14080 (2013) Timber structures-glued laminated timber and glued solid timber-requirements. European Committee for Standardisation, Brussels

21. WoodEye AB (2019) WoodEye. https://woodeye.com/. Accessed 1 Nov 2018

22. MiCROTEC (2018) MiCROTEC. https://microtec.eu/. Accessed 1 Nov 2018

23. Briggert A (2014) Fibres orientation on sawn surfaces - can fibre orientation on sawn surfaces be determined by means of high resolution scanning. Master thesis in structural engineering $15 \mathrm{hp}$, Department of Building Technology. Linnaeus University, Växjö, Sweden 
24. EN 13183-1/AC (2004) Moisture content of a piece of sawn timber-part 1: determination by oven dry method. European Committee for Standardisation, Brussels

25. Dinwoodie JM (2000) Timber: its nature and behaviour. E \& FN Spon, London
Publisher's Note Springer Nature remains neutral with regard to jurisdictional claims in published maps and institutional affiliations. 